\title{
An Arduino-Based Alternative to the Traditional Electronics Laboratory
}

\author{
R. B. Yoder \\ Dept. of Physics and Astronomy, Goucher College, 1021 Dulaney Valley Rd, Baltimore, MD 21204
}

\begin{abstract}
We have developed a project-based alternative approach to the traditional electronics laboratory course, incorporating a hands-on sequence of guided but open-ended activities. The Arduino microprocessor is incorporated from the beginning, which allows greatly enhanced scope and flexibility for projects and increases student motivation and agency. The course is designed for junior physics majors without significant experience in circuit design and construction. Students are given an orientation to the Arduino in the second week, and almost immediately begin constructing usable devices. As the projects grow more complex during the course, students are gradually introduced to the usual range of electronic components. The Arduino is particularly suited to measurement and control processes that are common in research environments, and the project themes emphasize signal production, detection, and analysis, including logging, filtering, and amplifying. By using the Arduino to control special-purpose ICs, students learn to read and interpret a datasheet. The course has now run once, with good learning outcomes and very positive student evaluations.
\end{abstract}

Keywords:.electronics, laboratory, Arduino, project-based learning

PACS: $01.50 . \mathrm{Qb}, 07.05 . \mathrm{Hd}$

\section{INTRODUCTION}

The physics program at Goucher College, like most, requires an electronics laboratory course (PHY310) for all majors. The reasons for the requirement include practical and pedagogical ones (solidifying basic concepts by embedding them in a practical context, adding hands-on lab work and measurement to the curriculum, developing useful technical skills). Fundamentally, the course aligns with a departmental philosophy that emphasizes the experimental nature of physics and aims to equip students for independent scientific exploration. A primary goal of the course, then, is to build student competence in device design and technical problemsolving. For those who continue in experimental physics, the course serves as an orientation to measurement and control systems and thus to modern laboratory work in general.

Until last year, PHY310 was a traditional electronics laboratory, in which students built and measured examples of (mostly analog) circuits, working from a standard textbook ${ }^{1}$ and progressing through a cookbook-style lab manual. The course material covered the familiar progression from DC and AC circuits to logic gates. Typical students were juniors and seniors with little previous experience in circuit building.

By 2014, the department had identified a number of unsatisfactory outcomes with the course. We saw a lack of student engagement with the material, and little motivation to assimilate unfamiliar concepts. Students could not easily describe connections between the material of PHY310 and their other courses. Most particularly, students reported that they did not see the value of the course material, or its usefulness for experimental work. At the same time, the course content no longer aligned well with current practice in research labs, where specialized computer-based instrumentation has become much more common and in which many projects require some coding. Our course goal of equipping students for independent lab work was not being met.

In response, PHY310 was completely redeveloped. We sought a course design that would keep students interested and motivated, that would promote independent work and problem-solving, and that would make an obvious connection with useful devices and measurement practices. We settled on the Arduino microprocessor platform ${ }^{2}$ as an enabling technology for the course. This paper reports, as a case study, on the initial roll-out of the new course and associated student outcomes.

\section{The Arduino Platform}

The Arduino is a simple open-source hardware platform that combines a microprocessor, memory, and signal input/output capability (both digital and analog). It is programmed using C. Used by students and hobbyists as well as professional developers, the basic Arduino can be customized and extended by a vast

2015 BFY Proceedings, edited by Eblen-Zayas, Behringer, and Kozminski; Peer-reviewed, doi:10.1119/bfy.2015.pr.027

Published by the American Association of Physics Teachers under a Creative Commons Attribution 3.0 license.

Further distribution must maintain attribution to the article's authors, title, proceedings citation, and DOI. 
assortment of hardware and software libraries. To create a useful device, of course, one must add appropriate circuitry; hence the value of Arduino for our course.

We found that Arduino had many advantages for classroom use. It is robust, simple, and easy to learn, with many teaching resources available, ${ }^{3}$ and can be operated with minimal background. Our students became comfortable quickly with the interface and the language, thanks to the simple examples included. As an open-source device, the Arduino is very inexpensive (starting at about $\$ 25)^{*}$, making it affordable for our department but also for students, some of whom chose to purchase their own. The availability of open-source programs and designs for many tasks was valuable for students' independent projects.

As a teaching tool, Arduino gives immediate and gratifying results: adding even a very simple circuit gives a device that performs a useful function. For example, with only a knowledge of resistor dividers, students can construct a fairly accurate resistancebased light or temperature sensor. We anticipated that these fast results would increase student engagement and motivation. Students who had previously heard of Arduino were likely to be especially interested in learning how to use one.

The Arduino has certain basic limitations as well; for example, it can only produce digital (high/low) output and has strictly limited output currents. However, working within the limitations is also instructive: students now have a reason to learn techniques for amplification, isolation, and filtering, and with each technique they are able to perform more demanding tasks with Arduino.

\section{COURSE DESIGN}

\section{Key Principles}

Several key principles guided the course design and influenced the content, process, and level of the course.

First, we realized at the outset that a one-semester course cannot make inexperienced students into experts in electronic circuits. Rather than aiming for mastery, the course's goal was to provide a kind of orientation - one that would equip students to develop necessary mastery later in their science careers, if and when needed. A key component of this equipping is the ability to find and understand relevant information, particularly component datasheets and circuit reference books; student exercises included explicit practice in this skill, and a unit on specialized ICs was mainly

\footnotetext{
* However, for greater longevity when mishandled, we highly recommend the ruggedized version available from www.ruggedcircuits.com.
}

aimed at developing datasheet comprehension. Recognizing that many physicists are not skilled electronics engineers, but rely on an ability to implement and modify known circuit solutions, one of the course objectives was for students to "knowledgeably implement" circuit designs from reference sources. The "assigned text" was intended as one such reference source.

Second, we chose to focus on processes, rather than components. That is, we were able to demonstrate the relevance of the course material by framing it broadly around the standard tools of the research lab-signal acquisition, manipulation, and control-with circuit components used as a means to these ends. This led naturally to lab exercises using real-world examples and devices as much and as early as possible. While we introduced most of the standard electronic components in the course of the semester, each was presented in the context of a process that it enabled.

Finally, a major goal of our course was to foster creativity and independence in the students, particularly in the context of building and modifying useful devices. This implied that the course should be project-based as much as possible. Students worked, usually alone, on self-paced tutorial-style labs, each culminating in a more open-ended project. By midterm, students had a choice of several week-long projects to attempt, and the course concluded with a final project of the student's choosing. A portion of the final project grade reflected the degree to which students made use of components or techniques not included explicitly in the course (and students were given a small budget for components). Classroom time also emphasized troubleshooting skills.

In order to give maximum attention to creative design and problem-solving as course goals, we eliminated formal lab reports, instead requiring only short answers to tutorial questions, occasional homework problems, and accurate circuit diagrams for projects.

\section{Organization of Topics}

Table 1 shows the organization of course topics. The table shows that the various electronic components are still introduced in a fairly traditional sequence, increasing in complexity, but that each is embedded in a device or measurement problem.

\section{OUTCOMES}

The initial offering of the course in Spring 2014 enrolled 9 students. Class standing ranged from sophomore to senior. While a few students had some expertise with programming, none had experience with 
circuit construction beyond the basic circuits they had seen in their introductory physics course.

TABLE 1. Outline of material and components covered during the initial run of the course, Spring 2014.

\begin{tabular}{|c|c|c|}
\hline Week & Technical topic or component & Project or device \\
\hline 1 & Review of voltage, resistance, power & Resistor divider \\
\hline 2 & Orientation to Arduino and programming & Customizing example programs \\
\hline 3 & First project: measuring DC signals with Arduino & Light sensor using photocell \\
\hline $4-5$ & $\begin{array}{l}\text { AC circuits, frequency response, and filters } \\
\text { (Capacitance, inductance, decay, passbands) }\end{array}$ & Output plus sensing: capacitance meter using $\mathrm{RC} d$ \\
\hline 6 & Diodes and rectification; transformer basics & Simple power supply \\
\hline 7 & Intro to IC's and pinouts & Control LCD display with Arduino \\
\hline $7-8$ & Midterm project & Options involve sensing and logging \\
\hline $9-11$ & Transistors, amplifiers, op amps & $\begin{array}{l}\text { High-current outputs: bright LEDs, motors and } \\
\text { motor drivers, audio signals, pulse-width } \\
\text { modulation }\end{array}$ \\
\hline 12 & Specialized ICs & $\begin{array}{l}\text { Digital clock (binary communication with clock } \\
\text { chip), remote control (infrared receiver) }\end{array}$ \\
\hline 13 & Feedback and control & Magnetic levitation \\
\hline $14-15$ & Final project period & Supervised independent work \\
\hline
\end{tabular}

Anecdotally, the Arduino platform stimulated student interest and engagement from the beginning. Several students began extending the projects beyond the requirements by the third week of class. At least half of the students conceived of a long-term goalsomething to build or invent as a final project-during the first half of the course.

As a measure of the degree to which the course reached its objectives, students' final projects were evaluated along five dimensions using a rubric. Table 2 presents results for those students who completed the course $(N=7)$. Though this sample is very small, the high average score for "competence" (a measure that rates the correct functioning and design of the circuitry) seems to be worth noting. While most of the other results are adequate to strong, we found that students did not demonstrate as much ability to incorporate material beyond that covered in the course ("extension") as we had expected.

TABLE 2. Average rating of students' final projects on various attributes $(5=$ excellent, $1=$ inadequate $)$. Standard deviations are in parenthesis.

\begin{tabular}{l|c}
\hline Quality rated & Mean rating (SD) \\
\hline $\begin{array}{l}\text { Successful and correct } \\
\text { circuitry ("competence") }\end{array}$ & $4.47(0.59)$ \\
\hline $\begin{array}{l}\text { Problem-solving sophistication } \\
\text { ("insight") }\end{array}$ & $3.57(0.98)$ \\
\hline $\begin{array}{l}\text { Ability to succeed without } \\
\text { assistance ("independence") }\end{array}$ & $4.07(1.0)$ \\
\hline $\begin{array}{l}\text { Going beyond course material } \\
\text { ("extension") }\end{array}$ & $2.86(1.3)$ \\
\hline $\begin{array}{l}\text { Novel combinations or } \\
\text { repurposing ("creativity") }\end{array}$ & $3.29(1.5)$ \\
\hline
\end{tabular}

Student course evaluations were used as a direct measure of student satisfaction and motivation, and for comparison with typical physics-department courses. Numerical ratings are shown in Table 3. We particularly note the high percentage of students finding that the coursework "contributed to their understanding of the material."

TABLE 3. Student ratings from course evaluations $(5=$ strongly agree/excellent, 1 = strongly disagree/poor), compared with the average response for all physics courses $(N=48)$ in the Spring 2014 semester. ${ }^{\ddagger}$ Standard deviations were not available for the departmental average.

\begin{tabular}{l|c|c}
\hline Statement/Question & $\begin{array}{c}\text { Mean rating } \\
(\text { SD })\end{array}$ & $\begin{array}{c}\text { Physics } \\
\text { Dept mean, } \\
\text { SP14 }\end{array}$ \\
\hline $\begin{array}{l}\text { Lab exercises were } \\
\text { pertinent to course } \\
\text { objectives }\end{array}$ & $4.8(0.4)$ & 4.4 \\
\hline $\begin{array}{l}\text { The course was } \\
\text { difficult }\end{array}$ & $3.2(0.9)$ & 2.6 \\
\hline $\begin{array}{l}\text { Work contributed to } \\
\text { understanding } \\
\text { material }\end{array}$ & $4.5(0.8)$ & 3.85 \\
\hline $\begin{array}{l}\text { How would you rate } \\
\text { this course? }\end{array}$ & $4.5(0.8)$ & 3.47 \\
\hline
\end{tabular}

Finally, we report a sampling of student comments, taken from the (anonymous) course evaluations.

- "Working with electronics and the microprocessors was very fun."

- "Every assignment was fascinating."

- "The fact that it was hands on and experimental made the course interesting and different from other courses that I have taken thus far in Physics."

\footnotetext{
*This includes students in introductory and advanced courses; disaggregated data could not be obtained. A relatively small number of responses $(<20 \%)$ are from non-majors, however, and past data shows no significant difference between the responses of the two groups.
} 
- "[I had to think for myself] more than I have in any course before. This is probably my favorite course so far."

- "Most of the projects and labs involved testing our problem solving abilities to achiev[e] the desired objective."

- "I really enjoyed this course."

Several comments explicitly praised the openended nature of many projects, which often focused on a result ("create a circuit to do this") and left the method up to the student. The most common complaint was that the pacing was faster than optimal, though this was not universally agreed. In future iterations of the course, we may make more use of optional extensions to tutorials. As a further indication of student engagement, a couple of students commented that they were proud of their projects and would have liked an opportunity to present them to the class. (Final projects included various enhanced clocks, a light-seeking robot, an ultrasonic range indicator, a 5-note electronic organ, and a sensor-based pot-plant irrigation device.)

\section{CONCLUSION}

The preliminary course outcomes from our small initial sample have been very encouraging. Though we lack the data to draw strong statistical conclusionsboth due to the small sample and the absence of comparable data from the previous version of the course - the results appear to demonstrate that the course redesign was successful in reaching its aims. Anecdotally, student engagement was dramatically enhanced, as illustrated by student comments and the wide range of creative final projects elicited in addition to the subjective experience of the instructor.

We acknowledge, of course, that the course transformation from cookbook-style to project-based must itself be given due credit for increasing student motivation and improved learning outcomes. However, we argue that the Arduino platform was a key ingredient of this success, in that it both enabled and encouraged a high degree of flexibility, capability, and increased student agency at a very early point in the course. We found that the platform lent itself naturally to project design and that developing the course syllabus and tutorials became straightforward. Though we encountered a little skepticism about students' ability to assimilate standard circuit concepts and techniques using only Arduino projects, our initial results indicate that such skepticism is unfounded. The Arduino was also, by itself, an effective motivator for many students, who were attracted by its reputation and "coolness."

The project-based approach seemed to elicit a reasonable degree of independence, with students demonstrably gaining skill in troubleshooting and circuit design. However, we find that it is more challenging for students to gain the confidence and initiative needed to pursue further topics on their own. We are studying ways that this might be included more specifically in the course design.

The course will be offered again in Fall 2015 with a much larger group of students, and we intend to further refine our approach after this second trial.

\section{ACKNOWLEDGMENTS}

Thanks to Ben Sugerman and Sasha Dukan for advice and encouragement, and to the students of PHY310 in Spring 2014. The course redesign was supported by a grant from the Crosby Fund for Excellence in Teaching, Goucher College.

\section{REFERENCES}

1. For example, A. J. Diefenderfer and B. E. Holton, Principles of Electronic Instrumentation, 3rd ed. (Saunders College, Philadelphia, 1994).

2. See www.arduino.cc.

3. Helpful resources include S. Monk, Programming Arduino: Getting Started with Sketches (McGraw-Hill, New York, 2012); S. Monk, Programming Ardino: Next Steps (McGraw-Hill, New York, 2014); J. Blum, Exploring Arduino (Wiley, Indianapolis, IN, 2013); and S. Monk, 30 Arduino Projects for the Evil Genius, 2nd ed. (McGraw-Hill Education, New York, 2013).

4. P. Scherz and S. Monk, Practical Electronics for Inventors, 3rd ed. (McGraw Hill, New York, 2013). 